University of Nebraska - Lincoln

DigitalCommons@University of Nebraska - Lincoln

$8-21-2020$

\title{
Future Themes and Forecasts for Research Libraries and Emerging Technologies
}

\author{
Scout Calvert \\ University of Nebraska-Lincoln, scout.calvert@unl.edu \\ Mary Lee Kennedy \\ Clifford Lynch \\ CNI \\ John O'Brien
}

Follow this and additional works at: https://digitalcommons.unl.edu/libraryscience

Part of the Library and Information Science Commons

Calvert, Scout; Kennedy, Mary Lee; Lynch, Clifford; and O'Brien, John, "Future Themes and Forecasts for Research Libraries and Emerging Technologies" (2020). Faculty Publications, UNL Libraries. 419. https://digitalcommons.unl.edu/libraryscience/419

This Article is brought to you for free and open access by the Libraries at University of Nebraska-Lincoln at DigitalCommons@University of Nebraska - Lincoln. It has been accepted for inclusion in Faculty Publications, UNL Libraries by an authorized administrator of DigitalCommons@University of Nebraska - Lincoln. 


\section{Future Themes and Forecasts for Research Libraries and Emerging Technologies}

Scout Calvert, Data Librarian, Michigan State University

Edited by Mary Lee Kennedy, Clifford Lynch, and John O'Brien

August 21, 2020 


\section{Table of Contents}

Executive Summary $\quad 3$

Introduction _ _ _ _ _

Key Findings $\quad 6$

Drivers and Signals of Change $\quad 8$

Forecasts and Future Themes 10

For Learning and Research Libraries 10

For Research and Research Libraries 13

Epilogue: Post-workshop Commentary and Opinion 16

$\begin{array}{ll}\text { Conclusion } & 18\end{array}$

Endnotes $\quad 19$ 


\section{Executive Summary}

Given the proliferation of powerful emerging technologies available to research organizations, how should research libraries plan to adopt and engage with these technologies in pursuit of their missions in the near term of the next one to three years? How has the critical role of research libraries in the use and adoption of emerging technologies been amplified, refined, or changed as research organizations pivoted to respond to the novel coronavirus pandemic?

In two workshops, held a month apart in the first weeks of the US pandemic response, leaders and experts in learning and research were guided through a series of exercises to identify likely futures for partnerships with libraries for emerging technologies in learning and research, respectively. As experts identified current drivers of change and signals that indicate that change is happening, they envisioned future trajectories for research libraries to engage with emerging technologies for learning and research in the near time frame of one to three years, and pandemic-caused disruptions loomed large in those trajectories. These potential futures are grounded in the experience and expertise of 27 workshop participants from the higher education learning, information, and research sectors.

Considering crucial, current drivers of change, we find the following trends and opportunities for research libraries:

- Collaborative, collective approaches to emerging technology challenges or endeavors that transcend a single unit, institution, region, or research library will be increasingly needed, valued, and expected.

- In the face of uncertainties about higher education, participants anticipate research libraries are poised to engage in shaping the future of their institutions in higher education from a position of strength.

- The pandemic drew attention to collaborative and cloud tools to support the focus on online teaching and research continuity, testing barriers to open data and scholarship. Experiments and improvisations can be expected to continue, with new constraints. 
- Data generated and used in research, learning, and as a byproduct of digital life will continue to drive a variety of projects in every part of the higher education project, and data-intensive research will continue to gain momentum.

\section{Introduction}

In 2019, months before the novel coronavirus emerged, the Association of Research Libraries (ARL), the Coalition for Networked Information (CNI), and EDUCAUSE formed a partnership to investigate how research libraries, as collaborators in the research and learning enterprise, can advance research and learning during times of significant changes in the production, dissemination, and reuse of digital content. A series of research reports and activities were planned, including the workshops that are the focus of this report. To lay the groundwork for these workshops, collaborators on the project interviewed dozens of leaders in technology and learning, research, and libraries, and produced two reports: Emerging Technologies for Research and Learning: Interviews with Experts ${ }^{1}$ and Mapping the Current Landscape of Research Library Engagement with Emerging Technologies in Research and Learning.

These reports prepared the partnership for the next phase of the project: to investigate strategies for technological adoption in research libraries. In our pre-pandemic planning, we hoped to gain insight into how research libraries should plan to adopt and engage with these technologies in pursuit of their missions in the near term of the next one to three years, given the proliferation of powerful emerging technologies available to research organizations, which were identified in the first phase work.

In pursuit of this insight, the team planned two workshops to be held at the EDUCAUSE Learning Initiative (ELI) Annual Meeting on March 4, 2020, and at the CNI Spring Membership Meeting on April 1, 2020. The workshop activities were modeled on the Institute for the Future IFTF Foresight Toolkit. ${ }^{-}$The toolkit is designed on the model of future-generative processes that assist organizations in planning by vividly imagining desirable and plausible futures and then determining the concrete actions 
required to bring those futures into being. We designed all-day workshops to guide two groups of about 15 people each from the learning and research communities through the process to generate forecasts for the near term of one to three years, to assist research libraries in proactively preparing to engage with emerging technologies for research and learning.

To launch our conversations, we defined emerging technologies generally as those with some degree of radical novelty, relatively fast growth, coherence, prominent impact, and uncertainty and ambiguity, ${ }^{4}$ but specifically gave examples drawn from recent ARL-CNI-EDUCAUSE

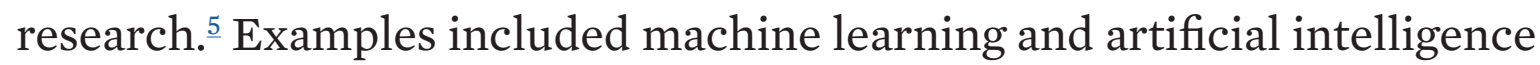
and the massive, heterogeneous data deluge that powers them, as well as the related technologies and tools that support machine learning and data use. We framed emerging technologies with reminders from Zuboff, 6 echoing Kranzberg,, 7 that technology is not neutral, and that human choices shape the use and adoption of technologies in social, political, and economic circumstances with both intended and unintended outcomes. This has been powerfully demonstrated by recent events.

However, the EDUCAUSE ELI meeting and the CNI meeting were among the earliest in-person conferences to be cancelled as the coronavirus outbreak arrived in North America. Both were replaced with virtual sessions; CNI immediately scheduled a virtual program that began on the original CNI meeting date, including two relevant roundtables on research continuity ${ }^{\underline{8}}$ and learning materials. ${ }^{-}$Our team quickly developed abridged workshops to be conducted via video conferencing. In our condensed online workshops, we worked together through the first steps of the process to identify some features of futures in which research libraries engage with powerful emerging technologies.

In our abbreviated forecasting activities, participants first identified drivers of change, "big forces reshaping today's landscape into something new" 10 in relation to emerging technologies for learning and research. Then, participants brainstormed signals of change related to a selection of drivers that were most urgent. Signals are concrete examples that show change is afoot. Clustering related signals in turn suggests possible futures. In our 
EDUCAUSE workshop, participants generated forecasts from the drivers and groups of signals. In our CNI workshop, participants gathered signals into future themes suggestive of forecasts. In this report, we synthesize the work of participants and refer to both forecasts and future themes as "forecasts," "scenarios," and "futures" because they are desirable and plausible trajectories based on identified drivers and signals of change. In both workshop groups, the enormity and uncertainty of the unfolding pandemic, along with initial institutional responses, loomed large in conversation.

\section{Key Findings}

In the synthesis of drivers, signals, forecasts, and themes from the workshops, four primary findings emerged:

Collaborative, collective approaches to emerging technology challenges or endeavors that transcend a single unit, institution, region, or research library will be increasingly needed, valued, and expected.

Again and again, as participants imagined scenarios in which their institutions overcame challenges or moved initiatives forward, crossinstitutional, cross-unit, and interdisciplinary partnerships played a crucial role in getting the work done. Cross-institutional examples include collective collections like Ivy Plus Libraries and Big Ten Academic Alliance, and the CADRE (Collaborative Archive \& Data Research Environment) project at Indiana University.

In the face of uncertainties about higher education, participants anticipate research libraries are poised to engage in shaping the future of their institutions in higher education from a position of strength.

Participants are keenly aware of financial, enrollment, and existential pressures on higher education that predated the pandemic, and they identified potential roles for research libraries in addressing intensified challenges. These roles include taking effective action for student success, preparing students for a variety of workplaces, innovating for ongoing education and career re-tuning, illustrating the versatility of liberal arts 
education for every workplace, and providing for civic education and literacy for both work readiness and the public good.

The pandemic drew attention to collaborative and cloud tools to support the focus on online teaching and research continuity, testing barriers to open data and scholarship. Experiments and improvisations can be expected to continue, with new constraints.

Participants identified immediate responses and anticipated future pressures that will shape the strategies available to research libraries in the near horizon of one to three years, including policy changes and financial changes. Examples of such responses included the "all hands on deck" attempt to protect research continuity, support effective distance education, and provide resources electronically through digitization, open educational resources (OERs), new acquisition and licensing strategies, and data infrastructure.

Data generated and used in research, learning, and as a byproduct of digital life will continue to ground a variety of projects in every part of the higher education project, and data-intensive research will continue to gain momentum.

Data is the fuel of emerging technologies, and engaging with data is a critical priority in all futures that emerged from the workshop. This element had five associated facets appearing across multiple futures:

- The urgency to partner to actively develop data-centric research infrastructure will grow, and expertise provisioned collaboratively by research libraries and campus partners is central to these collaborations, as well as to disciplinary, regional, national, and international infrastructure.

- A continuum of data analysis skills will be required in every discipline, for students as learners and job seekers, for instructors, and for librarians. Research libraries will be expected to be part of acquiring these skills.

- Concurrently, research libraries, as sites of engagement with emerging technologies, will likely adopt, embed, and teach data ethics. 
- Data analysis and ethics are an integral part of a related need to address civic readiness and digital fluency for student success, and for the creation of informed citizens. Addressing this challenge will require the involvement of students, faculty, and librarians.

- Finally, research libraries will continue to participate in standards development and interoperability as they collaboratively build infrastructure for data, research objects, OERs, and scholarly communication (particularly open access initiatives), including for linked open data, data curation, and digital preservation, but crucially for future data privacy standards as well.

\section{Drivers and Signals of Change}

Our workshop activities centered on brainstorming drivers of change and signals that change is happening. We guided participants to identify drivers for their professional contexts and describe the ability of research libraries to shape and influence the drivers of change. From this generative exercise, participants prioritized a smaller set of drivers and brainstormed associated signals that indicate the nature and direction of the change in the coming year to three years. Together, drivers and signals suggested potential futures for emerging technologies for research and learning that bear on the work of research libraries.

The pandemic was a major driver, implicitly or explicitly influencing other drivers that predated SARS-CoV-2. However, in the four weeks that elapsed between workshops, the force of the pandemic as a factor was more apparent, and participants appeared to narrow discussion to fewer emerging technologies with a more obvious role to play in research and learning continuity. There was considerable overlap in the drivers of change brainstormed by the two groups. For members of the learning community, drivers of change pertained to momentum and disruption brought about by new waves of data-centric technologies and by the need for enhanced digital skills-not just for students but also for faculty. This group also saw larger social, economic, and political drivers at play across higher education, including financial and efficiency pressures. Similar 
drivers were identified from the research perspective, as participants saw changing incentive structures, disruption in finances and research due to the pandemic, and policy shifts to protect and support research and access to scholarly resources.

\section{Priority Drivers for Learning}

1. The need to deliver a wide range of remote, online, and hybrid instruction, and to shift fluidly among these

2. Incentives, opportunities, and pressures to partner with industry and vendors to teach employeridentified skills

3. Potentials for machine learning and data analytics to inform student success initiatives and promote efficiencies

4. Changing incentive structures for faculty, including for digital scholarship

5. Declining enrollments, changes in student demographic profile, and other financial pressures

6. Qualitative skills for 21st-century communication and collaboration and digital fluencies

7. Equity of digital access and openness: OERs, open access, open models, and "inclusive access" that is cognizant of disability accessibility

\section{Priority Drivers for Research}

1. Incentives from funding agencies, institutions, and libraries for collaborative and collective projects

2. The need to ensure research continuity and mitigate ripple effects as universities respond to the pandemic with campus closures

3. Financial and policy change across higher education in relation to the pandemic

4. Users and practitioners with modest technological skill sets but high need and desire to use mature but challenging technologies

5. Shift to data-driven and online research, with concomitant need to grapple with privacy and ethics

6. Evolution and disruptions in scholarly communications

7. Research continuity in the face of lab closures, restricted travel (particularly internationally), and constraints on the availability of student research assistants 


\section{Forecasts and Future Themes}

In what follows, we summarize and synthesize these findings, and sometimes quote directly from the notes drafted collectively by participants. It is worth reiterating that the dates of the online workshops that produced the following forecasts and future themes straddled a rapid series of institution- and state government-mandated closures and shelterin-place orders. Our workshop with EDUCAUSE ELI participants came just days after the EDUCAUSE cancellation but just before the first waves of university closures. Our workshop with CNI participants came after most universities had taken steps to move to remote learning, and had limited campus access for most employees, including researchers. These unfolding developments, and ambiguity in the face of many unknowns, deeply influenced our conversations.

\section{For Learning and Research Libraries}

In our March 4 workshops, participants anticipated almost a dozen plausible, interrelated, and sometimes conflicting possible futures for higher education and emerging technologies. In these futures, research libraries are viewed as ready partners because they are already engaged in activities that pertain to information literacy, data, and technology use. While the purpose of higher education was not explicitly on the agenda for discussion, anxiety about its future surfaced in several scenarios, heightened by the newly emerging pandemic.

Despite the momentous circumstances in which we held our online workshops, participants were largely, if guardedly, optimistic and determined. One forecast, which participants hoped to avert, foresaw the collapse of the liberal arts tradition in higher education and its replacement by a postsecondary system patterned on the demands of wealthy philanthropists from technology sectors. As they described it, "an outsized voice in curriculum specification" from large technology sector employers, divorced from curricular expertise, will see "humanities departments and degrees continue to close." The role of research libraries in universities will be tested. Nevertheless, as "alternatives to accreditation sidestep current 
firewalls for quality" in the liberal arts tradition, "employers continue to complain that their new hires are not effective in communication, collaboration, conflict management, creativity, and related skills" in this scenario.

Yet, playing out the same drivers and signals, participants anticipated a contrasting possibility, in which interdisciplinary study and emerging technologies informed strategies for education to meet the needs of learners to engage in civil society and as workforce participants. In this future, the learning enterprise is "able to demonstrate that a broad, liberal arts education provides the strongest basis for success in a range of professional pathways." Here, libraries play a role in adopting technologies to support "learning and life outcomes," rather than the other way around. This highlighted the need for technologically skilled college graduates who also have capacities for communication, conflict resolution, collaboration, and creativity that are nurtured in the liberal arts tradition, and expressed through current technology practices.

These two scenarios emerged from the same drivers identified in our activities, a recognition of the tensions in technology adoption: technologies on their own do not determine outcomes but are adopted in particular social, economic, and political contexts that inflect their development and use. This is illustrated clearly in the pandemic-driven pivots to online learning.

In related futures, partnerships with technology sectors are supportive and strategic, but higher education and the research enterprise lead the way. Here, "as demographics shift, funders and stakeholders are insisting that universities address disparities in access, learning outcomes, graduation rates, and eventual earning capacity." In the face of increasing enrollment and financial pressures, new efficiency models are developed, with careful exploration and use of emerging technologies for learning in a networked environment, and with abiding attention to educational access and outcomes, so that practices for deploying technologies are designed to reduce inequities. Here, research libraries "are a centralized point for skill development, service provision, technology platforms, and collaboration" for students, faculty, and staff. 
It is a given, in the future, that libraries will continue to provide collections for learning and research. However, the shape of those collections and how they are accessed will change. As stakeholders in OER support and infrastructure, and as curators and sources of data for learning and research, research libraries are also the most obvious "curators of virtual content" and guide preservation of 3D video and new media.

The forecasts recognized that college graduates will need new digital fluencies both for participation in civic life and to be competitive in the job market. Data literacy activities will move beyond the classroom "to civic and public engagement.” These fluencies aren't completely novel, but rather cultivate approaches to data and data-intensive technologies that require critical thinking and ethics, both of which are classically associated with the liberal arts tradition. Properly, digital fluencies (rather than atomized skills) prepare students for the jobs that will be available when they graduate, and also prepare them with an attitude of continuous learning for constantly changing social and economic contexts. Additionally, participants anticipated the kinds of digital literacies that will be necessary preparation for civic life and for the public good.

The cultivation of digital fluencies is fundamental to research library work, and a potent site for collaboration with faculty. There is also an increased demand for practical data science, not just in STEM fields, but for "tech minors that reach into the humanities and social sciences and in the workforce" as well. Since practical data science is "more applied than what some units and faculties are ready" to teach, there is an expectation that research libraries will be key to meeting this demand. Besides the current employment trend in data analysis and business analytics and similar job titles that can be addressed through data science programs, a baseline expectation for practical data analysis, visualization, and comprehension will grow, more quickly in some sectors but as a basic function of general undergraduate education.

Concurrently, faculty, technologists, and instructional designers will have increased access to student data that can drive personalization and student success activities, making use of machine learning to evaluate and improve 
student support. But the data can't do that without research about what they mean, or technological developments to implement those insights. In this future, "faculty development has become widely available to assist instructors with ethical considerations of using personalized student data in teaching." Research libraries will be part of conversations and research design to understand student data while addressing ethical use cases for collecting, analyzing, and reporting the data.

As part of larger conversations about personal data and digital trace data on campus and as a society, faculty "are also employing a new set of standards to help make meaning of the data" in an envisioned initiative to equip campuses "with a set of questions to ensure data is being used ethically which includes addressing the affordances and consequences of bias, culture, and technological parameters." Students will increasingly participate in these conversations as they practice digital fluency across disciplines. Research libraries, drawing on their strengths in the area of privacy and knowledge creation, their position as data collectors, and as key players in standards development, will be part, with other bodies, of articulating ethics standards for collecting, storing, and deploying different kinds of patron and student data so that privacy, consent, and analysis can be balanced.

\section{For Research and Research Libraries}

Quickly changing circumstances brought a starker mood to the April 1 conversations with CNI attendees. Financial pressures, heightened by pandemic instability, framed all visions of the future. Crucially, participants anticipated that financial pressures will amplify existing trends toward collective projects and collaborations across campus units or institutions, both for scale and as competitive funding opportunities incentivize collaboration. The collaborative development of infrastructure for interdisciplinary, data-intensive research is a keystone of this future and the present moment "has potential to be the tipping point."

Trends toward collaborations between research libraries and other campus or institutional actors intersected with a vision of the future in which research continuity is supported through careful application of 
emerging technologies, even through contingencies and uncertainties. Multi-institutional examples include collective collections like Ivy Plus Libraries and Big Ten Academic Alliance, and the CADRE data project at Indiana University. Cross-departmental collaboration will "bring to light the expertise the library has, that is not available elsewhere, in support of sponsored research." This involves the creation of hybrid services, built together with allies and advocates. As a hub for cross-disciplinary encounters, research libraries will develop robust research commons with concierge services that support data and computational research in "technology-rich spaces where expertise, connective venues, training, and programming can be brought together."

The library-as-hub could include consulate space in research libraries for partners from IT or digital scholarship. Here, as some researchers use the affordances of cloud computing and storage for continuity during physical facilities closures, research libraries are partners in building infrastructure, and teaching and promoting research methods that make use of these affordances. Efforts to ensure research continuity through emerging technologies will be genuinely interdisciplinary and will "make sure humanities data is in the cloud" too.

Already moving in this direction, our experts anticipated that the disruption of 2020 will hasten the pivot towards new skills and new ways of making technological research support visible in promotion and tenure systems, addressing the tensions in traditional tenure processes. Just as higher education at large is considering new forms of credentialing and other strategies to promote lifelong learning and workforce readiness, library professional training and credentialing will be reworked to meet this future. This entails a library culture shift that "incentivizes risk-taking, flexibility, and cross-departmental team-building," allowing libraries to take part in shaping emerging technologies through use and adoption, and through the framework of privacy and ethics.

Research libraries continue to develop technological skill sets, providing professional development opportunities for library staff, supported by evaluation and promotion systems that are "less prescriptive" and 
"more open." This allows librarians and library staff to "level up" in data science, bibliometrics, research impact, open science tools, and other knowledge required for digital scholarship support. Recognizing that some technologies can be challenging to use, even when they are mature, research libraries fill a skills gap by addressing emerging technologies internally and bringing this knowledge to campus partners and students. At times, this looks like being a connector "between humanities and computer science faculty" and at other times like "dismantling departmental boundaries and moving to an interdisciplinary, cross-domain model."

The most visible and anticipated way that research libraries rise to meet this future is through engaged participation in data-driven research and research conducted with the affordances of online technologies. Sometimes leading, and frequently through new or existing collaborative partnerships like CADRE and the Data Curation Network, research libraries will make data services and infrastructure available broadly. One signal that this future is on its way is when "researchers are able to treat data infrastructure as a common public utility, rather than a bespoke commodity." Data resources will develop in response to the "demand for large-scale digital corpora," including the ability to engage in text and data mining of journal article collections and other collections of text.

The present need for data management plan development and related research data support will grow along with the "proliferation of experimental reporting and publications" and "demand for publication opportunities," be it in "traditional journals or new forms" of publication that will heighten interest in research library publication platforms and support for open access. Emerging forms of data scholarship will be supported through continued participation in standards-setting activities, for example for ontologies, data ethics, and APIs. In this future, research libraries are integral to creating the interoperability required for data provision and integration across systems, and at the scale needed to support cross-institutional partnerships.

As faculty mobilized to quickly move instruction and learning support to online venues, resources and services provided by research libraries 
featured heavily, feeding an already growing expectation in society of openness and access via the internet. This was indicated by the Internet Archive's suspension of checkout limits on digitized materials, and the use of HathiTrust Emergency Temporary Access Service. One signal of change is the perception that "copyright is out of action" because of the coronavirus emergency, offering a taste of the possibilities of openness. With it, participants detected "a strong sense of convergence across all levels of research funding and infrastructure toward assuming openness as a general condition," even if, in reality, there's a long way to go.

The future is expected to manifest ongoing evolutions and disruptions in the scholarly communications sphere. Continuing the perception that collaboration and partnership are motifs in all of the futures foreseen in the workshops, research libraries continue facilitating these changes, some in parallel with research infrastructure development for data support. Here, scholarly communications and data scholarship continue a related trajectory, as new tools and new research outputs require the development of tracking and incentive structures for academic credit. This evolution will drive the automation and enhancement of curatorial practices, as digital stewardship and preservation continue to be understood as the province of research libraries.

\section{Epilogue: Post-workshop Commentary and Opinion}

What have we learned since April?

When the ARL-CNI-EDUCAUSE team hosted the first workshop on March 4, there had been a wave of conference cancellations and announcements about initial mitigation strategies from universities. By April 1, many universities and schools had been closed for two or three weeks. As universities acted decisively to close campuses, it was unclear exactly how long labs and other facilities would be closed. But in our April 1 workshop, there was still room for optimism that the closures would not be particularly long-lived. While discussion focused on both immediate needs and near-term potentials for emerging technologies, there was a sense that technologies still in development would help-if they were already in place. 
As Kranzberg ${ }^{11}$ and Zuboff ${ }^{12}$ remind us, technology is never neutral. It is adopted in particular social contexts and shaped by a variety of interests with intended and unintended consequences. Zoom bombing and the swift move to pass-fail grading options are two examples of unintended consequences of the sudden and mass shift to distance learning. As Kranzberg theorizes, "nontechnical factors take precedence in technologypolicy decisions." 13 As we attempt to identify the roles that emerging technologies can play in providing continuity in research and learning during the pandemic, contextual factors will play an unpredictable role in adoption.

Even now, debate rages about the wisdom and safety about returning to campus in the fall, even with hybrid options. Campuses are anticipating dire financial consequences due to decreases in every revenue stream. Some tools that are still experimental could help, but they will not be ready soon enough to soften the blow caused by the emergency pivot to remote instruction. We can anticipate a rush to adopt tools that compromise student privacy, have poor terms of service that allow the ungoverned use of student data, and ignore accessibility concerns. There is a risk that innovations that take root in a time of crisis are ushered past the kind of scrutiny for accessibility, equity, and ethics that research libraries and individuals across the education sector have championed, and that the experts in the workshop envisioned as a crucial aspect of research library futures. There is also a risk that, while the research and learning enterprise is busy bailing water, developments in the private sector that forge new uses of emerging technologies will cast the die of ownership of those technologies.

Two specific factors seem worth dwelling on for research libraries: the need for online tools and resources to replace or augment real-time, faceto-face instruction that will persist through the pandemic and shape learning at every level long after; and the need for data in many forms, from large, multidisciplinary digitized and digital text corpora to aggregations of data sets big and small, to allow a modicum of research continuity given lab closures and travel bans. 
Kranzberg notes that technologies always come in packages,,$\underline{14}$ and it is up to research libraries to engage these technologies to be part of the package that is the context of their adoption for learning and research. Those packages of course involve the infrastructures that make them possible, as well as the service and support layers that make them function. As Edwards et al. write, $\underline{15}$ "All infrastructures embed social norms, relationships, and ways of thinking, acting, and working." Research libraries have the opportunity to broadcast their existing activities and expertise in these areas and stand out in virtual and physical space where many people are urgently seeking help with emerging technologies, and thus embed norms of openness, sharing, and collaboration in emerging technologies as they are adopted and adapted for research and learning.

The challenges ahead are about where bodies can be and still do the work of research and learning, and the limits and potentials of emerging technologies to reach across those constraints. The purpose of our workshops, as formulated before even the first known illness in Wuhan, was to bring experts together to imagine desirable and plausible futures to help inform the concrete actions required to bring those futures into being, over the coming one to three years. The coronavirus pandemic will be a driver of change for at least that time period. The next step is to identify realistic and concrete steps to bring desirable futures into being.

\section{Conclusion}

The coronavirus pandemic has affected nearly every aspect of research library work, and it appears as a driver of change explicitly or implicitly in the potential futures that emerged from discussion in our two workshops held in early spring 2020. We are far from knowing how the cascade of impacts will play out, but given the uncertain situation, our expert participants in the workshop nevertheless identified signals that the changes brought about by the pandemic are impacting the use and adoption of emerging technologies for learning and research by research libraries. Based on the synthesis of the forecasts and future themes, we anticipate that collaborative, collective approaches to emerging technology 
challenges or endeavors that transcend a single research library will be increasingly valued and expected. Research libraries hold a vital position to shape higher education despite uncertainties, and this should embolden research libraries to engage partners and technologies strategically. The coronavirus pandemic intensified pressures and accelerated experiments and improvisations with technologies-primarily those already available to instructors and researchers-to meet stopgap research and learning needs, including with data and scholarly openness. This innovation can be expected to continue as we learn what works to meet these needs and others that arise due to social distancing. Finally, continuing the prepandemic trajectory, data generated and used in research, learning, and as a byproduct of digital life will continue to ground a variety of projects to make good use of these assets in every part of the higher education project, and interest in data analysis and infrastructure will also intensify due to the related financial and enrollment pressures. Current events largely amplify pressures and opportunities for research libraries to mindfully and collaboratively adopt and shape emerging technologies to advance the mission in support of learning and research.

\section{Endnotes}

1. Scout Calvert and Mary Lee Kennedy, Emerging Technologies for Research and Learning: Interviews with Experts, ed. Clifford Lynch and John O'Brien (Association of Research Libraries, Coalition for Networked Information, and EDUCAUSE, 2020), https://doi. org/10.29242/report.emergingtech2020.interviews.

2. Sarah Lippincott, Mapping the Current Landscape of Research Library Engagement with Emerging Technologies in Research and Learning, ed. Mary Lee Kennedy, Clifford Lynch, and Scout Calvert (Association of Research Libraries, Born-Digital, Coalition for Networked Information, and EDUCAUSE, 2020), https://doi.org/10.29242/report. emergingtech2020.landscape.

3. IFTF Foresight Toolkit: Practical Tools for Foresight, Insight, and Action (Palo Alto: Institute for the Future, 2018). 
4. Daniele Rotolo, Diana Hicks, and Ben R. Martin, "What Is an Emerging Technology?," preprint, submitted February 13, 2015, last revised January 4, 2016, https://arxiv.org/abs/1503.00673.

5. Calvert and Kennedy, Emerging Technologies, and Lippincott, Mapping the Current Landscape.

6. Shoshana Zuboff, In the Age of the Smart Machine: The Future of Work and Power (New York: Basic Books, 1988).

7. Melvin Kranzberg, “Technology and History: 'Kranzberg's Laws,"” Technology and Culture 27, no. 3 (1986), 544-60, https://doi. org $/ 10.2307 / 3105385$.

8. What Happens to the Continuity and Future of the Research Enterprise? Report of a CNI Executive Roundtable Series Held April 2020 (Coalition for Networked Information, May 2020), https://www.cni.org/go/whathappens-to-continuity-and-future-of-research.

9. New Strategies for Acquiring Learning Materials: Report of a CNI Executive Roundtable Series Held March 30-31, 2020 (Coalition for Networked Information, June 2020), https://www.cni.org/go/newstrategies-for-acquiring-learning-materials.

10. IFTF Foresight Toolkit.

11. Kranzberg, "Technology and History."

12. Zuboff, In the Age of the Smart Machine.

13. Kranzberg, “Technology and History," 550.

14. Kranzberg, 549.

15. Paul N. Edwards et al., Knowledge Infrastructures: Intellectual Frameworks and Research Challenges (Ann Arbor: Deep Blue, 2013), http://hdl.handle.net/2027.42/97552. 